\title{
Aqueous immune mediators in malignant uveal melanomas in comparison to benign pigmented intraocular tumors
}

\author{
Yoshihiko Usui $^{1}$ (D) Kinya Tsubota ${ }^{1} \cdot$ Tsuyoshi Agawa $^{1} \cdot$ Shunichiro Ueda $^{1} \cdot$ \\ Kazuhiko Umazume $^{1}$ - Yoko Okunuki ${ }^{1}$ Takeshi Kezuka ${ }^{1}$. \\ Naoyuki Yamakawa ${ }^{1} \cdot$ Hiroshi Goto ${ }^{1}$
}

Received: 21 February 2016 /Revised: 12 October 2016/Accepted: 31 October 2016/Published online: 22 November 2016

(C) The Author(s) 2016. This article is published with open access at Springerlink.com

\begin{abstract}
Background To examine the usefulness of measuring immune mediators in aqueous humor samples for differentiating malignant uveal melanoma from benign pigmented intraocular tumors.

Methods Thirteen eyes of 13 patients with uveal melanoma were studied, and 13 eyes of 13 patients with benign pigmented intraocular tumors served as controls. Undiluted samples of aqueous humor were collected, and a cytometric bead array was used to determine the aqueous humor concentrations of 35 immune mediators comprising 14 interleukins (IL), interferon- $\gamma$, interferon- $\gamma$-inducible protein-10, monocyte chemoattractant protein (MCP)-1, macrophage inflammatory protein (MIP)- $1 \alpha$, MIP- $1 \beta$, regulated on activation normal $\mathrm{T}$ cell expressed and secreted, monokine induced by interferon- $\gamma$, basic fibroblast growth factor, Fas ligand, granzyme A, granzyme B, eotaxin, interferon-inducible T-cell alpha chemoattractant, fractalkine, granulocyte macrophage colony-stimulating factor, granulocyte colony-stimulating factor, vascular endothelial growth factor, angiogenin, tumor necrosis factor- $\alpha$, lymphotoxin- $\alpha$, and CD40L.

Results Aqueous humor levels of angiogenin, IL-8, and MCP-1 were significantly higher in eyes with malignant melanoma than in those with benign tumors $(p<0.05)$.
\end{abstract}

Electronic supplementary material The online version of this article (doi:10.1007/s00417-016-3541-5) contains supplementary material, which is available to authorized users.

Yoshihiko Usui usuyoshi@gmail.com

1 Department of Ophthalmology, Tokyo Medical University Hospital, 6-7-1 Nishi-shinjuku, Shinjuku-ku Tokyo 160-0023, Japan
Conclusions Angiogenin, IL-8, and MCP-1 levels in aqueous humor may be potential markers for distinguishing malignant uveal melanoma from benign pigmented intraocular tumors, and may be a useful adjunct to histomorphology, diagnostic imaging, and other biomarkers for the diagnosis and appropriate clinical management of malignant uveal melanoma.

Keywords Benign pigmented intraocular tumor · Uveal melanoma $\cdot$ Immune mediator

\section{Introduction}

Differentiation between malignant and benign pigmented intraocular tumors is currently based on comprehensive clinical ophthalmoscopic examination and imaging findings. Histopathological or cytological features are the gold standard for diagnosis of pigmented intraocular tumors, although choroidal biopsy may be inherently associated with some seeding risk. Almost all malignant pigmented intraocular tumors are uveal melanomas. Although many tumor markers for uveal melanoma have been reported, no such marker has been established for differentiating melanoma from benign tumors. Treatment for ocular malignancy is enucleation in certain tumor conditions, and the lack of good diagnostic markers for pigmented uveal tumors may lead to inappropriate or inadequate treatment [1]. Thus, it is important to establish the grade and risk of pigmented intraocular tumors before surgery in order to provide adequate treatment. To this end, new markers that can distinguish malignant uveal melanoma from other benign pigmented tumors are needed. Immune mediators are present in the aqueous humor of eyes with malignant uveal melanoma [2, 3], both as inflammatory reactions and induced by growth of the melanoma. The number of inflammatory 
cells has been shown to correlate with prognosis [4]. In addition, aqueous flare is influenced by the size of the uveal melanoma [5]. The aim of the present study was to examine the usefulness of measuring immune mediators in aqueous humor samples to differentiate between malignant uveal melanoma and benign pigmented intraocular tumors.

\section{Methods}

The study included 13 immunocompetent patients ( 6 men and 7 women; mean age $59.2 \pm 14.3$ years) with uveal melanoma in the choroid. The control group comprised 13 patients (4 men and 9 women; mean age $57.5 \pm 19.1$ years), as follows: one patient with a perivascular epithelioid cell tumor in the ciliary body, one with mesectodermal leiomyoma in the ciliary body, four with melanocytoma in the ciliary body, two with adenomas in the ciliary body, three with nevi in the ciliary body, one with nevus in the iris, and one with hypertrophy of the retinal pigment epithelium. Figure 1 shows representative anterior segment photographs of control patients, with findings mimicking malignant uveal melanoma. In all patients, diagnoses were made based on clinical, diagnostic imaging [magnetic resonance imaging (MRI) and B-scan ultrasonography], and histologic data.

Benign pigmented intraocular tumors were treated conservatively in five cases and by local resection in eight cases. Uveal melanomas were treated by enucleation in 12 cases and local resection in one case. Local resection of uveal melanomas was performed as described previously [6]. Briefly, phacoemulsification and aspiration were performed, followed by scleral flap dissection. The base of the sclera and the uvea containing the tumor were incised and subsequently removed, together with the iris, which was radially dissected in advance. After the scleral flap was replaced and sutured, vitrectomy was performed to remove the vitreous hemorrhage.

Undiluted aqueous humor samples were collected before cataract surgery, local resection, or enucleation. The samples were stored immediately at $-80{ }^{\circ} \mathrm{C}$ until assayed. For histological examination, enucleated eyes or specimens were fixed in $4 \%$ formaldehyde solution and embedded in paraffin. Sections were cut, stained with hematoxylin and eosin, and immunolabeled with human melanoma black 45 (HMB-45) and $\mathrm{S} 100$.

The CBA Flex immunoassay kit (BD Biosciences, San Jose, CA, USA) was used to determine the aqueous humor concentrations of 35 immune mediators comprising interleukins (IL)-1 $\alpha$, IL-1 $\beta$, IL-2, IL-3, IL-4, IL-5, IL-6, IL-8, IL-9, IL-10, IL-11, IL-12p70, IL-17A, and IL-21, interferon (IFN)- $\gamma$, interferon- $\gamma$-inducible protein (IP)-10, monocyte chemoattractant protein (MCP)-1, macrophage inflammatory protein (MIP)- $1 \alpha$, MIP- $1 \beta$, regulated on activation normal T cell expressed and secreted (RANTES), monokine induced by interferon- $\gamma$ (Mig), basic fibroblast growth factor (bFGF), Fas ligand, granzyme A, granzyme $\mathrm{B}$, eotaxin, interferoninducible T-cell alphachemoattractant (ITAC), fractalkine, granulocyte macrophage colony-stimulating factor (GM$\mathrm{CSF}$ ), granulocyte colony-stimulating factor (G-CSF), vascular endothelial growth factor (VEGF), angiogenin, tumor necrosis factor (TNF)- $\alpha$, lymphotoxin- $\alpha$, and CD40L. Simultaneous

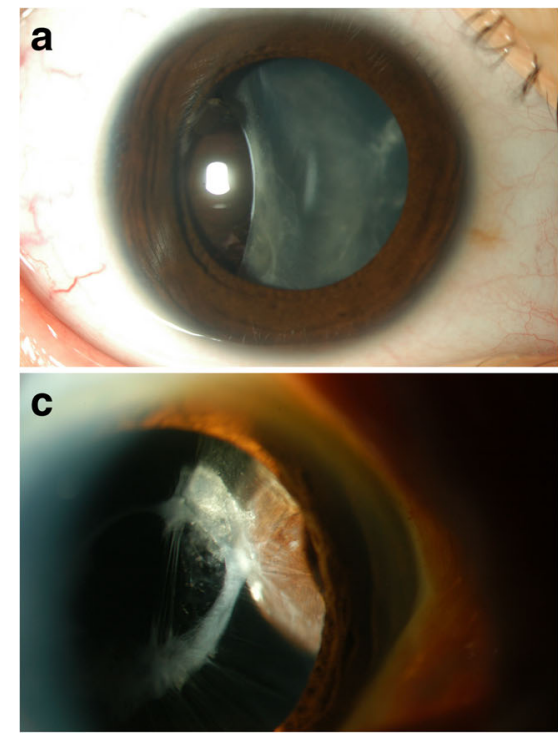

Fig. 1 Clinical spectrum of benign pigmented intraocular tumors mimicking malignant uveal melanoma. a Case 1: Primary perivascular epithelioid cell tumor (PEComa). Slit-lamp photograph shows a brown mass located temporally, with deformed and tilted lens. b Case 2: Mesectodermal leiomyoma. Gonioscopic photograph shows a mass

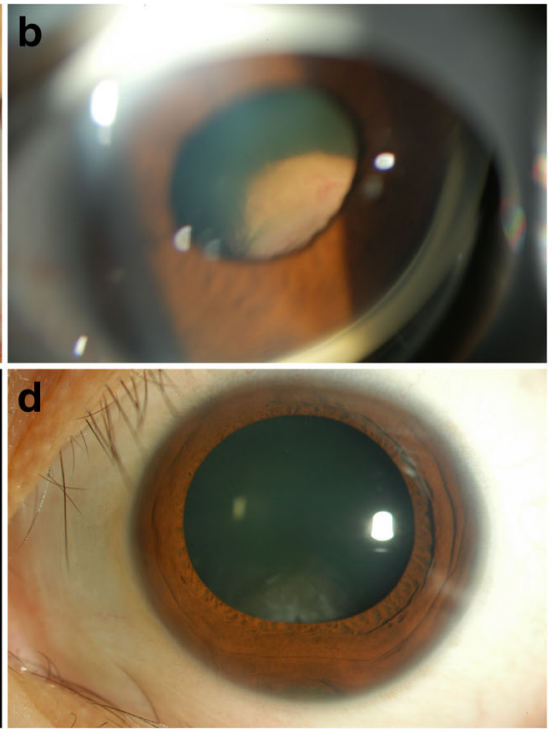

located in the superior nasal quadrant of the ciliary body, displacing the iris and lens. c Case 3: Melanocytoma. Slit-lamp photograph shows a pigmented mass located in the nasal quadrant of the ciliary body. d Case 4: Melanocytoma. Slit-lamp photograph shows a tumor invading the angle encroaching upon the lens inferiorly 
detection of many analytes was able to be performed with a very small sample volume, as described previously [7]. The lowest detectable concentration of this assay was $1.0 \mathrm{pg} / \mathrm{ml}$ for all immune mediators tested. This study was approved by the institutional review board of Tokyo Medical University, and all patients gave written informed consent. All patients were Japanese adults.

Statistical analyses were performed using JMP version 12 software (SAS Institute Inc., Cary, NC, USA). Two-group comparisons of numerical variables were performed using Student's $t$ test or the Mann-Whitney $U$ test, based on the data distribution pattern. The nonparametric Mann-Whitney $U$ test was used to analyze immune mediator levels, because the data were not normally distributed.

\section{Results}

The characteristics of all patients are summarized in Tables 1 and 2, and the aqueous humor levels of the immune mediators are summarized in Table 3. Aqueous humor levels [mean (range) $\mathrm{pg} / \mathrm{ml}$ ] of angiogenin, IL-8, and MCP-1 were significantly higher in uveal melanoma than in benign pigmented intraocular tumors [angiogenin: 21962.4 (4978.7-84479.6) $\mathrm{pg} / \mathrm{ml}$ vs. $7071.6(0-11589.6) \mathrm{pg} / \mathrm{ml}, p<0.05$; IL-8: 525.6 (16.0-3428.7) pg/ml vs. $33.3(0-128.6) \mathrm{pg} / \mathrm{ml}, p<0.01$; MCP-1: 2416.7 (600.1-7723.0) pg/ml vs. 533.7 (117.31712.3) $\mathrm{pg} / \mathrm{ml}, p<0.001]$. The levels of these three upregulated immune mediators in individual patients are shown in Tables 1 and 2. The levels of the other immune mediators were not significantly different between the groups, and many were below the level of detection (Table 3).

Although aqueous VEGF concentration has been reported to be significantly up-regulated in uveal melanoma compared to cataract, the aqueous humor level of VEGF in uveal melanoma in this study was not significantly elevated compared to benign intraocular pigmented tumors [mean (range) VEGF level: $275.0(0-1993.7) \mathrm{pg} / \mathrm{ml}$ vs. $55.4(0-146.0) \mathrm{pg} / \mathrm{ml}, p=$ $0.18]$. We found no expression or very low levels of VEGF $(<50 \mathrm{pg} / \mathrm{ml})$ in $23.1 \%$ of the 13 patients.

Other ocular lesions may mimic melanoma (pseudomelanomas), and age-related macular degeneration (AMD) is one of the pseudomelanomas commonly encountered clinically [8]. Therefore, we compared cytokine expression profiles in uveal melanoma and ARMD. Angiogenin, MCP-1, and IL-8 were significantly up-regulated in uveal melanoma compared to ARMD (Supplementary Table 1), similar to the results of the comparison with benign tumors. In addition, IL-6, Mig, and IP-10 levels were higher in uveal melanoma than in ARMD, probably due to the stronger inflammatory state in uveal melanoma.

\section{Discussion}

Uveal melanoma often causes ocular inflammation and flare in the anterior chamber [5, 9]. Tumor-infiltrating lymphocytes are detected in $5 \%$ to $12 \%$ of uveal melanoma [4], and correlate with high flare values [9]. Infiltrating inflammatory cells such as macrophages and lymphocytes often exist in cancer tissues, and are believed to exert anti-tumor effects through immune surveillance. However, inflammation in the tumor microenvironment has many cancer-promoting effects that facilitate the proliferation and survival of malignant tumors, and promote angiogenesis and metastasis [10]. Various cytokines are detected in uveal melanoma, and they are produced by either tumor cells or infiltrating immune cells [11]. Melanoma cells in culture express large numbers of cytokines

Table 1 Clinical data and aqueous humor levels of angiogenin, IL-8, and MCP-1 in all patients with benign pigmented intraocular tumors

\begin{tabular}{|c|c|c|c|c|c|c|c|c|c|c|c|}
\hline No. & Gender & $\begin{array}{l}\text { Age } \\
\text { (years) }\end{array}$ & $\begin{array}{l}\text { Size } \\
(\mathrm{L}, \mathrm{W}, \mathrm{H} \mathrm{mm})\end{array}$ & $\begin{array}{l}\text { Tumor } \\
\text { location }\end{array}$ & $\begin{array}{l}\text { Histological } \\
\text { diagnosis }\end{array}$ & $\begin{array}{l}\text { Presence of } \\
\text { subretinal } \\
\text { detachment }\end{array}$ & $\begin{array}{l}\text { Angiogenin } \\
(\mathrm{pg} / \mathrm{ml})\end{array}$ & $\begin{array}{l}\text { IL-8 } \\
(\mathrm{pg} / \mathrm{ml})\end{array}$ & $\begin{array}{l}\text { MCP-1 } \\
(\mathrm{pg} / \mathrm{ml})\end{array}$ & Treatment & Follow-up \\
\hline 1 & $\mathrm{~F}$ & 13 & $10,9,8$ & $\mathrm{CB}$ & PEComa & - & 5490 & 5 & 117 & Local resection & $71 \mathrm{M}$ \\
\hline 2 & $\mathrm{~F}$ & 41 & $6,4,2$ & $\mathrm{CB}$ & $\begin{array}{c}\text { Mesectodermal } \\
\text { leiomyoma }\end{array}$ & - & 6513 & 64 & 332 & Local resection & $60 \mathrm{M}$ \\
\hline 3 & $\mathrm{~F}$ & 46 & $8,8,7$ & $\mathrm{CB}$ & Melanocytoma & - & 4244 & 0 & 262 & Local resection & $55 \mathrm{M}$ \\
\hline 4 & $\mathrm{~F}$ & 67 & $10,9,7$ & $\mathrm{CB}$ & Melanocytoma & - & 8866 & 129 & 1712 & Local resection & $67 \mathrm{M}$ \\
\hline 5 & M & 59 & $8,7,7$ & $\mathrm{CB}$ & Melanocytoma & + & 0 & 52 & 1021 & Local resection & $28 \mathrm{M}$ \\
\hline 6 & M & 60 & $6,5,5$ & $\mathrm{CB}$ & Melanocytoma & + & 5946 & 7 & 401 & Local resection & $64 \mathrm{M}$ \\
\hline 7 & $\mathrm{~F}$ & 49 & $8,7,6$ & $\mathrm{CB}$ & Adenoma & - & 9616 & 72 & 497 & Local resection & $39 \mathrm{M}$ \\
\hline 8 & M & 40 & $6,4,6$ & $\mathrm{CB}$ & Adenoma & + & 8468 & 87 & 544 & Local resection & $33 \mathrm{M}$ \\
\hline 9 & $\mathrm{~F}$ & 70 & $3,2,1$ & Retina & Hypertrophy of RPE & - & 11589 & 3 & 514 & Observation & $27 \mathrm{M}$ \\
\hline 10 & M & 70 & $10,7,8$ & Iris & Nevus & - & 9592 & 8 & 648 & Observation & $20 \mathrm{M}$ \\
\hline 11 & $\mathrm{~F}$ & 78 & $5,4,4$ & Choroid & Nevus & - & 8575 & 0 & 328 & Observation & $69 \mathrm{M}$ \\
\hline 12 & $\mathrm{~F}$ & 76 & $4,3,3$ & Choroid & Nevus & - & 4453 & 7 & 235 & Observation & $56 \mathrm{M}$ \\
\hline 13 & $\mathrm{~F}$ & 79 & $3,2,1$ & Choroid & Nevus & - & 8575 & 0 & 328 & Observation & $32 \mathrm{M}$ \\
\hline
\end{tabular}

$\mathrm{IL}=$ interleukin; $\mathrm{MCP}=$ monocyte chemoattractant protein; $\mathrm{F}=$ female; $\mathrm{M}=$ male; $\mathrm{NA}=$ not available; $\mathrm{CB}=$ ciliary body; $\mathrm{PEComa}=$ primary perivascular epithelioid cell tumor; RPE = retinal pigment epithelium 
Table 2 Clinical data and aqueous humor levels of angiogenin, IL-8, and MCP-1 in all patients with uveal melanoma

\begin{tabular}{|c|c|c|c|c|c|c|c|c|c|c|}
\hline No. & Gender & $\begin{array}{l}\text { Age } \\
\text { (years) }\end{array}$ & $\begin{array}{l}\text { Size } \\
\text { (L, W, H mm) }\end{array}$ & $\begin{array}{l}\text { Tumor } \\
\text { location }\end{array}$ & $\begin{array}{l}\text { Histological } \\
\text { type }\end{array}$ & $\begin{array}{l}\text { Presence of } \\
\text { subretinal } \\
\text { detachment }\end{array}$ & $\begin{array}{l}\text { Angiogenin } \\
(\mathrm{pg} / \mathrm{ml})\end{array}$ & $\begin{array}{l}\text { IL-8 } \\
(\mathrm{pg} / \mathrm{ml})\end{array}$ & $\begin{array}{l}\text { MCP-1 } \\
(\mathrm{pg} / \mathrm{ml})\end{array}$ & Treatment \\
\hline 1 & $\mathrm{~F}$ & 75 & $16,12,7$ & Choroid & Spindle B & - & 9022 & 287 & 1198 & Enucleation \\
\hline 2 & F & 85 & $8,2,2$ & Choroid & Mixed & - & 5432 & 34 & 600 & Local resection \\
\hline 3 & M & 59 & $18,12,10$ & Choroid & Mixed & + & 13446 & 17 & 636 & Enucleation \\
\hline 4 & M & 56 & $3,3,1$ & Choroid & Mixed & - & 16521 & 76 & 1805 & Enucleation \\
\hline 5 & $\mathrm{~F}$ & 65 & $9,8,8$ & Choroid & Mixed & + & 18920 & 63 & 2683 & Enucleation \\
\hline 6 & F & 57 & $9,8,6$ & Choroid & Mixed & - & 14480 & 419 & 3220 & Enucleation \\
\hline 7 & $\mathrm{~F}$ & 37 & $15,13,12$ & Choroid & Mixed & -- & 6824 & 3429 & 7723 & Enucleation \\
\hline 8 & M & 54 & $14,6,7$ & Choroid & Mixed & + & 4979 & 2153 & 7277 & Enucleation \\
\hline 9 & $\mathrm{~F}$ & 41 & $12,11,10$ & Choroid & Mixed & + & 5252 & 16 & 910 & Enucleation \\
\hline 10 & M & 41 & $15,12,9$ & Choroid & Mixed & + & 23717 & 114 & 1911 & Enucleation \\
\hline 11 & $\mathrm{~F}$ & 76 & $16,11,14$ & Choroid & Mixed & + & 70877 & 100 & 1511 & Enucleation \\
\hline 12 & M & 59 & $14,14,12$ & Choroid & Mixed & + & 11162 & 55 & 721 & Enucleation \\
\hline 13 & M & 65 & $16,14,12$ & Choroid & Mixed & + & 84480 & 68 & 1222 & Enucleation \\
\hline
\end{tabular}

$\mathrm{IL}=$ interleukin; $\mathrm{MCP}=$ monocyte chemoattractant protein $; \mathrm{F}=$ female $\mathrm{M}=$ male; $\mathrm{NA}=$ not available

and growth factors $[12,13]$, and melanoma-derived cytokines and growth factors exert paracrine effects on intraocular and inflammatory cells. Conversely, cytokines and growth factors produced by inflammatory tumor cells can stimulate malignant cells. Thus, cytokines and growth factors in the uveal melanoma microenvironment may regulate the functions of both malignant and inflammatory cells, possibly affecting the mechanism of tumor progression.

To the best of our knowledge, there are no reports of markers for differentiating uveal melanoma from benign pigmented intraocular tumors. We previously described the presence of cystoid macular edema due to a high concentration of VEGF in the vitreous [14], which was tentatively explained by the presence and elevated level of VEGF in benign intraocular tumors. Several studies have demonstrated an essential role of VEGF as a prognostic marker of the aggressiveness of uveal melanoma $[2,15,16]$. In the present study, the aqueous humor VEGF level was not significantly increased in uveal melanoma compared to benign intraocular pigmented tumors. The discrepancy in findings between studies may be explained in part by the selection of controls. When we compared the mean aqueous humor VEGF level in the present series of uveal melanoma patients with that in cataract patients $(23.1 \mathrm{pg} / \mathrm{ml}, \mathrm{n}=30)$, the level was significantly elevated in uveal melanoma patients (data not shown). Vinores et al. [17] reported VEGF expression in $26 \%$ of uveal melanomas, while others have reported that VEGF was absent in uveal melanomas $[18,19]$. Therefore, VEGF may not be a specific marker for malignant uveal melanoma because aqueous humor VEGF levels do not differentiate between benign pigmented intraocular tumors and malignant uveal melanoma.

Angiogenin acts as a growth factor for melanocytes. As such, angiogenin is thought by some to represent an autocrine growth factor in malignant melanoma of the skin, and has been reported to predict treatment response in patients with metastatic cutaneous melanoma [20]. The present study, however, is the first to show upregulation of angiogenin in uveal melanoma. Thus, angiogenin may have an important role in melanoma-related angiogenesis and may represent an important target of anti-angiogenic therapy.

MCP-1 and IL-8 - a chemokine and cytokine, respectively, with important roles in inflammation-are potent chemotactic factors primarily for macrophages and neutrophilic granulocytes. IL-8 is known to be a potent growth factor for human malignant melanoma [21-23]. In the present study, both MCP-1 and IL-8 were up-regulated in the aqueous humor of patients with uveal melanoma. Whether uveal melanoma cells or the infiltrating immune cells produced these mediators, however, is unknown. Uveal melanoma is considered an immunogenic tumor, because of the identification of numerous tumor-associated antigens. It is possible that because infiltrating immune cells react more strongly to malignant tumors than to benign tumors, they produce more MCP-1 and IL-8 in response to malignant uveal melanoma. In fact, we found a significant correlation between the number of CD3positive cells $/ \mathrm{mm}^{2}$ in melanoma specimens and aqueous MCP-1 $\left(\mathrm{R}^{2}=0.47, p=0.01\right)$ as well as IL-8 levels $\left(R^{2}=\right.$ $0.63, p=0.0011)$, but not angiogenin level $\left(R^{2}=0.007, p=\right.$ 0.78) (data not shown). Furthermore, MCP-1 and IL-8 have been reported to be up-regulated in rhegmatogenous retinal detachment [24]. In the current study, the prevalence of subretinal detachment was higher in uveal melanoma than in benign pigmented tumors (Tables 1 and 2). Therefore, the presence of subretinal detachment may contribute to the elevated aqueous MCP-1 and IL- 8 levels in patients with uveal melanoma. Additional studies are needed to elucidate the functional role of angiogenin, IL-8, and MCP-1 in uveal melanoma.

The present study has some limitations, including its retrospective nature, the relatively small sample size, and 
Table 3 Immune mediator levels in aqueous humor of patients with malignant and benign pigmented intraocular tumors

\begin{tabular}{|c|c|c|c|}
\hline & Malignant $(n=13)$ & Benign $(n=13)$ & $p$ value \\
\hline Angiogenin (pg/ml) & $21962.4(4978.7-84479.6)$ & $7071.6(0-11589.6)$ & 0.0257 \\
\hline bFGF (pg/ml) & $21.0(0-259.7)$ & $6.1(0-27.7)$ & 0.6629 \\
\hline CD40 ligand (pg/ml) & 0 & 0 & \\
\hline Eotaxin $(\mathrm{pg} / \mathrm{ml})$ & 0 & 0 & \\
\hline Fas ligand (pg/ml) & $75.9(0-807.7)$ & $157.2(0-1565.4)$ & 0.3833 \\
\hline Fractalkine (pg/ml) & $3.2(0-15.9)$ & $23.8(0-298.8)$ & 0.6081 \\
\hline G-CSF (pg/ml) & $1.1(0-7.8)$ & $14.6(0-105.3)$ & 0.3833 \\
\hline GM-CSF (pg/ml) & 0 & 0 & \\
\hline Granzyme A (pg/ml) & $0.3(0-1.8)$ & $7.7(0-74.5)$ & 0.5554 \\
\hline Granzyme B (pg/ml) & $0.3(0-3.7)$ & $13.6(0-167.6)$ & 0.4887 \\
\hline IFN- $\gamma(\mathrm{pg} / \mathrm{ml})$ & $0.4(0-5.4)$ & $0.5(0-6.3)$ & 0.9795 \\
\hline $\mathrm{IL}-1 \alpha(\mathrm{pg} / \mathrm{ml})$ & 0 & 0 & \\
\hline $\mathrm{IL}-1 \beta(\mathrm{pg} / \mathrm{ml})$ & 0 & 0 & \\
\hline IL-2 (pg/ml) & 0 & 0 & \\
\hline IL-3 (pg/ml) & 0 & 0 & \\
\hline IL-4 (pg/ml) & 0 & 0 & \\
\hline IL-5 (pg/ml) & $2.7(0-19.2)$ & 0 & 0.505 \\
\hline IL-6 (pg/ml) & $1185.8(2.1-13635.8)$ & $196.8(0-683.4)$ & 0.7005 \\
\hline IL-8 (pg/ml) & $525.6(16.0-3428.7)$ & $33.3(0-128.6)$ & 0.0052 \\
\hline IL-9 (pg/ml) & 0 & 0 & \\
\hline IL-10 (pg/ml) & $2.9(0-27.7)$ & 0 & 0.3173 \\
\hline IL-11 (pg/ml) & $0.8(0-10.3)$ & $15.0(0-194.8)$ & 0.9795 \\
\hline IL-12p70 (pg/ml) & 0 & 0 & \\
\hline IL-17A (pg/ml) & $0.4(0-2.6)$ & $5.5(0-68.7)$ & 0.9183 \\
\hline IL-21 (pg/ml) & $3.0(0-38.6)$ & $41.3(0-500.5)$ & 0.7389 \\
\hline IP-10 (pg/ml) & $1133.9(60.8-7540.0)$ & $310.0(0-1550.4)$ & 0.0687 \\
\hline ITAC (pg/ml) & 0 & 0 & \\
\hline $\mathrm{LT}-\alpha(\mathrm{pg} / \mathrm{ml})$ & 0 & 0 & \\
\hline MCP-1 (pg/ml) & $2416.7(600.1-7723.0)$ & $533.7(117.3-1712.3)$ & 0.0002 \\
\hline Mig (pg/ml) & $1727.8(0-13496.1)$ & $141.9(11.8-553.6)$ & 0.209 \\
\hline MIP-1 $\alpha(\mathrm{pg} / \mathrm{ml})$ & $0.2(0-2.5)$ & $0.9(0-10.4)$ & 0.7389 \\
\hline MIP-1 $\beta(\mathrm{pg} / \mathrm{ml})$ & $21.9(0-125.4)$ & $22.3(0-64.8)$ & 0.7005 \\
\hline RANTES (pg/ml) & $131.5(0-1710.9)$ & $15.9(0-207.3)$ & 0.2592 \\
\hline $\mathrm{TNF}-\alpha(\mathrm{pg} / \mathrm{ml})$ & 0 & 0 & \\
\hline VEGF (pg/ml) & $275.0(0-1993.7)$ & $55.4(0-146.0)$ & 0.1824 \\
\hline
\end{tabular}

Immune mediator levels are expressed as mean (range).

$\mathrm{bFGF}=$ basic fibroblast growth factor; G-CSF = granulocyte colony-stimulating factor;

GM-CSF = granulocyte macrophage colony-stimulating factor; $\mathrm{IFN}=$ interferon; $\mathrm{IL}=$ interleukin;

IP-10 = interferon gamma-induced protein $10 \mathrm{kDa}$; ITAC = interferon-inducible T-cell alphachemoattractant;

LT- $\alpha=$ lymphotoxin $-\alpha$ MCP = monocyte chemoattractant protein;

Mig $=$ monokine induced by interferon $\gamma ;$ MIP = macrophage inflammatory protein;

RANTES $=$ regulated upon activation normal $\mathrm{T}$ expressed and presumably secreted;

$\mathrm{TNF}=$ tumor necrosis factor; $\mathrm{VEGF}=$ vascular endothelial growth factor sample selection. In addition, the study design does not allow examination of the evolution of the aqueous humor immune mediator profile over time. Further studies with a larger number of the patients and longer follow-up are crucial for confirming the roles of angiogenin, $\mathrm{MCP}-1$, and IL-8. Other types of benign pigmented intraocular tumors, such as hemangioma, osteoma, metastatic uveal tumors, and granuloma of the uvea [8], were not examined. Furthermore, 
we compared malignant melanoma only with benign pigmented tumors in this study. However, some of the choroidal melanomas are amelanotic, and pigmentation may not be the main discriminating factor. Other non-pigmented tumors that masquerade as malignant melanoma must also be studied. Despite these limitations, however, to our knowledge, this is the first study comparing the usefulness of various immune mediators for distinguishing between malignant uveal melanoma and benign pigmented intraocular tumors.

The results of the present study demonstrate that angiogenin, MCP-1, and IL- 8 in the aqueous humor were significantly up-regulated in malignant uveal melanoma and may be potential markers for distinguishing uveal melanoma from benign pigmented intraocular tumors. These markers may also be a useful adjunct to histomorphology and diagnostic imaging techniques such as MRI, optical coherence tomography (OCT), and fluorescein angiography for determining the diagnosis and deciding appropriate clinical management. Large-scale studies are necessary to evaluate whether angiogenin, MCP-1, and IL-8 in the aqueous humor are specific and sensitive markers of malignant uveal melanoma.

Acknowledgments This study was supported by the Tokyo Medical University Cancer Research Foundation; a Grant-in-Aid for Scientific Research (C) from the Ministry of Education, Culture, Sports, Science and Technology of Japan; and the 'Strategic Research-Based Support" Project for private universities; with matching funds from MEXT (Ministry of Education, Culture, Sports, and Science), Japan. We would also like to thank Dr. Teresa Nakatani for editorial assistance.

Author contributions Study design: YU

Collection, management, analysis, and interpretation of the data: $\mathrm{YU}$, KT, TA, SU, KU、YO, TK, NY, HG

Preparation of manuscript: YU, YO

Review and approval of manuscript: all

\section{Compliance with ethical standards}

Conflict of interest All authors certify that they have no affiliations with or involvement in any organization or entity with any financial interest (such as honoraria; educational grants; participation in speakers" bureaus; membership, employment, consultancies, stock ownership, or other equity interest; and expert testimony or patent-licensing arrangements) or non-financial interest (such as personal or professional relationships, affiliations, knowledge or beliefs) in the subject matter or materials discussed in this manuscript.

Funding No funding was received for this research.

Ethical approval All procedures performed in studies involving human participants were in accordance with the ethical standards of the institutional and/or national research committee and with the 1964 Declaration of Helsinki and its later amendments or comparable ethical standards.

Informed consent Informed consent was obtained from all individual participants included in the study.
Open Access This article is distributed under the terms of the Creative Commons Attribution 4.0 International License (http:// creativecommons.org/licenses/by/4.0/), which permits unrestricted use, distribution, and reproduction in any medium, provided you give appropriate credit to the original author(s) and the source, provide a link to the Creative Commons license, and indicate if changes were made.

\section{References}

1. Odashiro AN, Fernandes BF, Al-Kandari A, Gregoire FJ, Burnier MN Jr (2007) Report of two cases of ciliary body mesectodermal leiomyoma: unique expression of neural markers. Ophthalmology 114:157-161

2. Ly LV, Bronkhorst IH, van Beelen E et al (2010) Inflammatory cytokines in eyes with uveal melanoma and relation with macrophage infiltration. Invest Ophthalmol Vis Sci 51:5445-5451

3. Dunavoelgyi R, Funk M, Sacu S et al (2012) Intraocular activation of angiogenic and inflammatory pathways in uveal melanoma. Retina 32:1373-1384

4. Lang JR, Davidorf FH, Baba N (1977) The prognostic significance of lymphocytic infiltration in malignant melanoma of the choroid. Cancer 40:2388-2394

5. Castella AP, Bercher L, Zografos L, Egger E, Herbort CP (1995) Study of the blood-aqueous barrier in choroidal melanoma. Br J Ophthalmol 79:354-357

6. Goto H, Usui Y, Nagao T (2015) Perivascular epithelioid cell tumor arising from ciliary body treated by local resection. Ocul Oncol Pathol 1:88-92

7. Usui $Y$, Wakabayashi $Y$, Okunuki $Y$ et al (2012) Immune mediators in vitreous fluids from patients with vitreoretinal B-cell lymphoma. Invest Ophthalmol Vis Sci 53:5395-5402

8. Shields CL, Manalac J, Das C, Ferguson K, Shields JA (2014) Choroidal melanoma: clinical features, classification, and top 10 pseudomelanomas. Curr Opin Ophthalmol 25: 177-185

9. Kuchle M, Nguyen NX, Naumann GO (1994) Quantitative assessment of the blood-aqueous barrier in human eyes with malignant or benign uveal tumors. Am J Ophthalmol 117: 521-528

10. Trinchieri G (2012) Cancer and inflammation: an old intuition with rapidly evolving new concepts. Annu Rev Immunol 30:677-706

11. Bronkhorst IHG, Jager MJ (2013) Inflammation in uveal melanoma. Eye (Lond) 27:217-223

12. Mattei S, Colombo MP, Melani C, Silvani A, Parmiani G, Herlyn M (1994) Expression of cytokine/growth factors and their receptors in human melanoma and melanocytes. Int J Cancer 56:853-857

13. Rodeck U, Melber K, Kath R et al (1991) Constitutive expression of multiple growth factor genes by melanoma cells but not normal melanocytes. J Invest Dermatol 97:20-26

14. Suzuki J, Goto H, Usui M (2005) Adenoma arising from nonpigmented ciliary epithelium concomitant with neovascularization of the optic disk and cystoid macular edema. Am J Ophthalmol 139:188-190

15. Sheidow TG, Hooper PL, Crukley C, Young J, Heathcote JG (2000) Expression of vascular endothelial growth factor in uveal melanoma and its correlation with metastasis. Br J Ophthalmol 84: $750-756$

16. Missotten GS, Notting IC, Schlingemann RO et al (2006) Vascular endothelial growth factor a in eyes with uveal melanoma. Arch Ophthalmol 124:1428-1434

17. Vinores SA, Kuchle M, Mahlow J, Chiu C, Green WR, Campochiaro PA (1995) Blood-ocular barrier breakdown in eye with ocular melanoma. A potential role for vascular endothelial 
growth factor/vascular permeability factor. Am J Pathol 147:12891297

18. Stitt AW, Simpson DA, Boocock C, Gardiner TA, Murphy GM, Archer DB (1998) Expression of vascular endothelial growth factor (VEGF) and its receptors is regulated in eyes with intra-ocular tumours. J Pathol 186:306-312

19. Kvanta A, Steen B, Seregard S (1996) Expression of vascular endothelial growth factor (VEGF) in retinoblastoma but not in posterior uveal melanoma. Experimental eye research. Exp Eye Res 63: $511-518$

20. Song J, Wang J, Yang J, Jiang C, Shen W, Wang L (2006) Influence of angiogenin on the growth of A375 human melanoma cells and the expression of basic fibroblast growth factor. Melanoma Res 16: $119-126$
21. Kunz M, Hartmann A, Flory E et al (1999) Anoxia-induced upregulation of interleukin-8 in human malignant melanoma. A potential mechanism for high tumor aggressiveness. Am J Pathol 155: 753-763

22. Schadendorf D, Moller A, Algermissen B, Worm M, Sticherling M, Czarnetzki BM (1993) IL-8 produced by human malignant melanoma cells in vitro is an essential autocrine growth factor. J Immunol 151:2667-2675

23. Lattanzio L, Tonissi F, Torta I et al (2013) Role of IL-8 induced angiogenesis in uveal melanoma. Invest New Drugs 31:1107-1114

24. Yoshimura T, Sonoda KH, Sugahara M et al (2009) Comprehensive analysis of inflammatory immune mediators in vitreoretinal diseases. PLoS One 4:e8158 